\title{
A Surgical Approach: Para Aortic Nodal Recurrence of Sigmoid Adenocarcinoma
}

Para aortic node excision in sigmoid ACA

Maneka M Britto, * MBBS

Shanaka Perera, $\varphi$ MBBS

Saleh Alzharani,* MBBS, MS

Alexander Heriot, * MD, FRACS

Assoc. Prof Craig Lynch, * MBChB, FRACS

Satish K Warrier, $* \varphi$ MBBS, FRACS

* Department of Surgical Oncology, Peter MacCallum Cancer Centre, Melbourne, Victoria, Australia.

$\varphi$ Department of Colorectal Surgery, Alfred Health, Melbourne, Victoria, Australia.

Figures:

Word Count: 314

\section{Corresponding author:}

Mr Satish K Warrier

Department of Surgical Oncology

Peter MacCallum Cancer Centre

305 Grattan Street, Melbourne, VIC, 3000

Email: satish96101@yahoo.com

Corresponding author is not a recipient of a research scholarship.

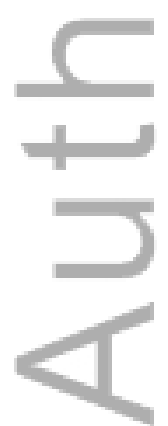

This is the author manuscript accepted for publication and has undergone full peer review but has not been through the copyediting, typesetting, pagination and proofreading process, which may lead to differences between this version and the Version of Record. Please cite this article as doi: 10.1111/ans.13806

This article is protected by copyright. All rights reserved. 
MeSH Keywords: Aorta, Abdominal; Colorectal Neoplasms; Lymph Node Excision;

Neoplasm Recurrence, Local; Chemoradiotherapy

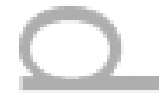

" Isolated para aortic lymph node involvement in metastatic colorectal cancer (CRC) is uncommon. Surgical salvage has been thought to be futile and technically challenging and with such disease considered appropriate for palliative chemotherapy.

A 28 year old female presented with radiological evidence of a para aortic nodal mass. She had previously undergone a Hartmann's procedure for a perforated sigmoid adenocarcinoma and subsequently received adjuvant chemotherapy.

Routine imaging performed a year later revealed residual lymph node disease in the left proximal iliac region, and interval growth noted on subsequent scans.

Despite receiving pre operative chemoradiotherapy, re-staging scans showed an illdefined para aortic lymph node that appeared inseparable from the abdominal aorta and the common iliac arteries. A decision was made to resect the nodal mass.

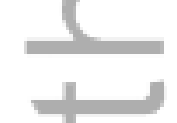

Intraoperatively, a confluent mass was seen extending between the inferior vena cava (IVC) and aorta and extending inferiorly to the left common iliac vessels.

Meticulous dissection was undertaken with complete macroscopic resection of the mass. Histological analysis showed microscopically clear resection margins.

This article is protected by copyright. All rights reserved. 
The incidence of isolated para aortic lymph nodes (PALN) in CRC has been reported as $1-2 \%{ }^{1}$. Due to its relatively uncommon metastatic pattern, the principles of treatment and prognosis of PALN in CRC have not been well addressed.

Vascular and para-aortic lymph node involvement in the region of the aortoiliac vessels in recurrent or metastatic colorectal cancer has been previously thought to be a general contraindication to surgical intervention. This is largely due to presumed complications, technical difficulties and poor long term survival rates ${ }^{2,3}$.

Previous reports have described enbloc resection of aorto-iliac disease for locally advanced CRC with lymph node metastasis. While this procedure was once considered palliative, our patient remains disease free at 2 years.

This case highlights that para-aortic lymph node dissection can be achieved with preservation of the IVC_upto the level of the renal vein and the aorto-iliac axis while achieving clear resection margins.

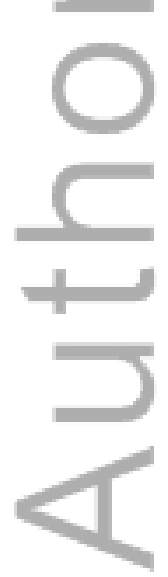

This article is protected by copyright. All rights reserved. 


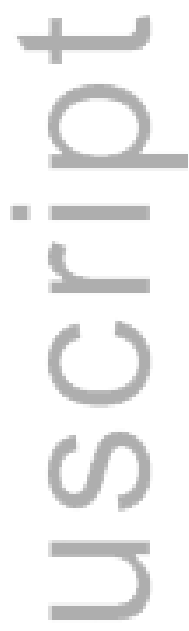

\section{References}

1. Gagniere J. Dupre A, Chabaud S, Peyrat P, Meeus P, Rivoire M. Retroperitoneal nodal metastases from colorectal cancer: Curable metastases with radical retroperitoneal lymphadenectomy in selected patients. Eur. J. Surg. Oncol. 2015;

41: 731-7.

2. Bouchard P, Efron J. Management of recurrent rectal cancer. Ann Surg Oncol. $2010 ; 17: 1343-1356$

3. Abdelsattar ZM, Mathis KL, Colibaseanu DT, Merchea A, Bower TC, Larson DW, Dozois EJ. Surgery for locally advanced recurrent colorectal cancer involving the aortoiliac axis: can we achieve R0 resection and long term survival?. Dis Colon Rectum. 2013; 56(6): 711-716

This article is protected by copyright. All rights reserved. 


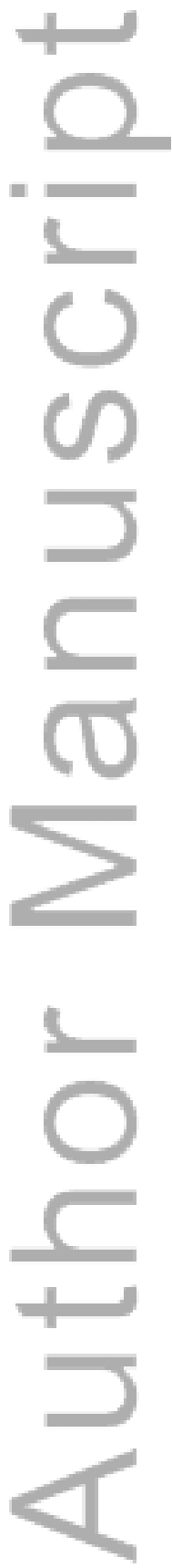

This article is protected by copyright. All rights reserved. 


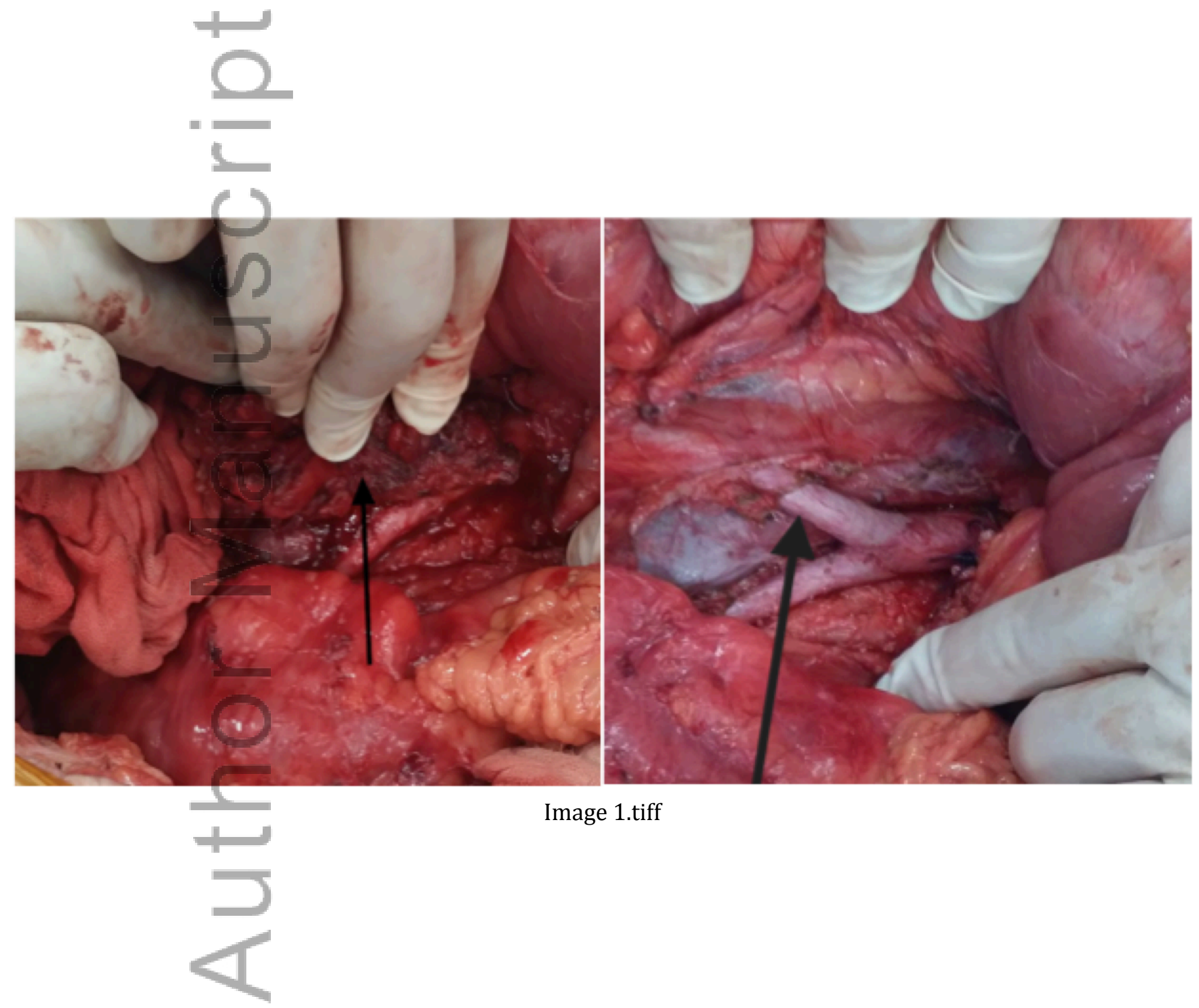

This article is protected by copyright. All rights reserved. 


\section{University Library}

\section{- M M N E R VA A gateway to Melbourne's research publications}

Minerva Access is the Institutional Repository of The University of Melbourne

Author/s:

Britto, MM;Perera, S;Alzharani, S;Heriot, A;Lynch, C;Warrier, SK

Title:

A surgical approach: para-aortic nodal recurrence of sigmoid adenocarcinoma

Date:

2017-03-01

Citation:

Britto, M. M., Perera, S., Alzharani, S., Heriot, A., Lynch, C. \& Warrier, S. K. (2017). A surgical approach: para-aortic nodal recurrence of sigmoid adenocarcinoma. ANZ JOURNAL OF SURGERY, 87 (3), pp.209-210. https://doi.org/10.1111/ans. 13806.

Persistent Link:

http://hdl.handle.net/11343/292588 